\title{
Application of Halliday's Register Model to Construction of Translation Quality Assessment Criteria in Translation Teaching Context
}

\author{
Nguyen Van Thao', Hoang Cong Binh ${ }^{2}, \operatorname{Herman}^{3}$ \\ ${ }^{1}$ Faculty of Philology, Hanoi Pedagogical University 2, Vinh Phuc, Vietnam \\ ${ }^{2}$ Faculty of Foreign Languages, Nha Trang University, Khanh Hoa, Vietnam \\ ${ }^{3}$ Department of English Education, Universitas HKBP Nommensen, Medan, Indonesia \\ Email address: \\ nguyenvanthao@hpu2.edu.vn (N. V. Thao),binhhc@ntu.edu.vn (H. C. Binh),herman@uhn.ac.id (Herman)
}

\section{To cite this article:}

Nguyen Van Thao, Hoang Cong Binh, Herman. Application of Halliday's Register Model to Construction of Translation Quality Assessment Criteria in Translation Teaching Context. International Journal of Applied Linguistics and Translation. Vol. 6, No. 2, 2020 , pp. $47-51$. doi: $10.11648 /$ j.ijalt.20200602.12

Received: April 2, 2020; Accepted: April 17, 2020; Published: April 30, 2020

\begin{abstract}
Translation quality assessment (TQA) is an essential link between translation theory and its practice, it is also an enjoyable and instructive exercise, particularly if you are assessing someone else's translated version or, even better, two or more translated renditions of the same text. Recently, in translation teaching context, translation assessments, conducted by teachers or even students, have appeared unsystematically and mainly based on a vast of subjective deduction or personal experiences; therefore the assessment activity in classrooms is limited in searching for translation errors or mistakes only and the learners also conduct translation exercises without any apparently-standardized criteria given in advance. This paper will present an empirical research on assessment activity through the application of Halliday's register model, applied to languagemajored students' translation assessment at a university in Vietnam, specifically at Faculty of Foreign Languages of Nha Trang University. To investigate the difference between the two selected groups of students, a survey on students' TQA activity will be conducted. The purposes of this survey are to see how the students carry out peer assessment activity and to measure to what extent the TQA activity also affects students' translation competence. To collect the data for the investigation, one group is instructed TQA criteria while the other are not introduced to the TQA criteria. The two selected groups also undertake the assessment activity of the same translated version. The results of this research will show the benefits of constructed criteria for TQA in learning and teaching translation at tertiary level.
\end{abstract}

Keywords: Register Theory, Translation Assessment Criteria, Linguistic Variables

\section{Introduction}

Translation quality assessment (TQA) was historically originated as long as translation activity [10]. The assessment of translator's performance is an activity which, despite being widespread, is under-researched and underdiscussed [6]. For centuries, translations have been carried out on the basis of stylistic criteria or according to the constant translation methods used. Translation evaluation is relevant to three areas of translation: the evaluation of published translations, the evaluation of professional translators' work and evaluation in translation teaching. Each area has different requirements of object, type, function, aim, and means for judging a translation. Up to now, most research into assessment in translation only concentrates on one area - evaluation of published translations - and other areas are ignored [11]. Nowadays, translation criticism in the world in general and in Vietnam in particular has been privately and unsystematically conducted; consequently, TQA has failed into error analyzing. In a ridiculously occurred case, a translated version was assessed by its nature, smoothness, while the assessor did not know about the source text (ST)and even the source language (SL). In international, national conferences and workshops on translation studies, TQA has played an auxiliary role despite scientists' efforts in this 
field. At present, most universities in Vietnam are expecting to fulfill two simultaneous training duties, which are teaching foreign language according to communicative orientation and teaching translation with professional goal. The requirements of these duties are not the same in terms of the learners' intake, teachers, methodology and even facilities. In reality, translation is one of the compulsory subjects in training program, in which TQA is an essential chapter of a translation course. In some cases, however, the teachers and the learners conduct TQA activities without any specific criteria given in advance. Thus, what are the criteria to state that one target text (TT) is a good translation, while another one is a bad or poor? Therefore, without having determined criteria, judging is vain, subjective and aimless.

In this paper, firstly, different TQA models will be briefly discussed. Secondly, Halliday's Register model will be described in details. Thirdly, based on the current situation, level of the students and purpose of training, the application of Halliday's register theory is about to construction of TQA criteria will be proposed. Lastly, it will be the findings of the surveys on TQA and translation activities for the two selected groups of language students in Nha Trang University Vietnam.

\section{Literature Review}

As mentioned earlier, criteria for evaluation of translation depend on one's approach and theory of translation. Likely, House stated "Evaluating the quality of a translation presupposes a theory of translation. Thus, different view of translation lead to different concepts of translational quality, and hence different ways of assessing it" [10]. In discussions about TQA, there isa variety of approaches to the problem: anecdotal and subjective including neo-hermeneutic approaches, response-oriented approaches, and text-based approaches [1].

\subsection{Newmark's TQA Model}

Newmark's model of evaluation includes the analysis of the source language text, a comparison of it and the translation, and comments about the translation's potential role as a translation [12]. He states that any comprehensive criticism of translation has to cover the following five procedures:

1) A brief analysis of the SL text stressing its intention and its functional aspect;

2) The translator's interpretation of the SL text's purpose, his translation method and the translation's likely readership;

3) A selective but representative detailed comparison of the translation with the original;

4) An evaluation of the translation: in translator's terms and in the critic's terms;

5) Where it is appropriate, and assessment of the likely place of the translation in the target culture or discipline.

\subsection{Christiane Nord's TQA Model}

In accordance with the Skopos theory, Nord considers functionality the most important criterion for a translation", meaning that no matter how logical it may seem at first, it is neither a ST or its effect on a recipient nor a function assigned to it by the author that operate the translation process [13]. According to Nord, the evaluator must take the target skopos as the starting point for TQA, assess the target text against the skopos and the translator's explicit strategies, and then do a source text/target text comparison for inferred strategies. Nord stressed that error analysis is insufficient: "It is the text as a whole whose functions and effects must be regarded as the crucial criteria for translation criticism" [13].

\subsection{Malcolm Williams's Model}

Based on the Argumentation theory designed by Malcolm Williams, he attempts to combine a non-qualitative and a qualitative approach to TQA [15]. The author himself states that "whatever the speciality or purpose, a translation must reproduce the argument structure of ST to meet the minimum criteria of adequacy" [15]. According to Williams, the quantitative approach of the theory is in the number of arguments correctly or incorrectly rendered by a translator, and the qualitative one in analyzing the arguments and dividing them into smaller components.

Generally, the above authors' models contain different approaches and make a great contribution to theoretical foundation in translation studies. In translation teaching context, however, those models sometimes overlap with each other and are rather complicated and difficultly used. As in Nord's TQA model, the judgment is not definitive. Indeed, she states that there "will be no overall evaluation of the translated text" [13]. Thus, how does she generate an overall assessment from the criterion-referenced comparisons, particularly when her judgment is based on the nature of the errors, not their number? Likely, Williams's model has some drawbacks - it is rather macro-structural analysis, and not all text must inevitably contain arguments. Moreover, the model does not take the context and cultural elements of texts into account. In translation teaching context, the rising questions are: whether a general theoretical framework is applicable for all text-type assessment or each text-type needs to be evaluated by distinctively constructed criteria?; TQA belongs to textual linguistics, so what translation units will be assessed to meet the duties in ELT context?

To solve the above problems, an overview of Halliday's Register model will be discussed before the application to TQA criteria construction.

\subsection{Halliday's Register Model}

When learning foreign languages, especially in translation, we often wonder why the native speakers can easily understand each other in all contexts, even when they whisper or there is a lot of noise around. In some cases, interlocutors can predict exactly what the speakers want to convey. Thus, how do they anticipate? The answer is that the 
interlocutors rely on the so called register/context of situation. In linguistics, a register is a variety of a language used for a particular purpose or in a particular setting. The term register was firstused by a linguist, Thomas Bertram Reid in 1956. and was brought into general currency in the 1960 s by a group of linguists who wanted to distinguish between variations in language according to the user (defined by variables such as social background, geography, sex and age), and variations according to use, "in the sense of that each speaker has a range of varieties and choices between them at different times" [3]. According to Halliday and Hasan, context of situation is the interaction between languages and the features of contexts [4]. Context here relates to the context of situation and context of culture, both of which exist in discourse by influencing the linguistic variables that discourse producers use. This interaction described by Hallidayis the three parameters: Field of discourse, Tenor of discourse and Mode of discourse. These parameters construct register or functional linguistic variables determining types of meaning in discourses.

\subsubsection{Field of Discourse}

Field refers to what is happening, to the nature of the social action that is taking place. In another word, field generally expresses ideational metafunction, where language represents social experiences, activities and understanding of the world [8]. It uses language to represent knowledge and belief, and is normally realized through the language features of clauses, nouns, verbs and adjectives. Different languages develop different fields of discourse in different ways [5].

\subsubsection{Mode of Discourse}

Mode is expressed through textual metafunction which gives a text its cohesion. That the discourse appears in written or spoken form is the choice of mode.

\subsubsection{Tenor of Discourse}

Tenor is expressed through interpersonal metafunction which defines the process of social interaction, especially the relationship between the participants in events. Those social interaction and relationship can be formality, politeness, impersonality and accessibility.

The term translation itself can refer to the subject field, the product or the process and a translated version can be assessed by authorities, companies, organizations, experts, teachers, translator trainees and readers etc... And what should be held as the criteria for TQA is the core and current concern of all debates in translation studies. Regrettably, however, the register approach has not found much application in translation studies until 1990s when translation theorists realized the nature of translation as a textual thing [9]. Thus, to develop criteria for TQA in translation teaching context is quite necessary, practical and indispensable.

Although the three parameters (field, mode, tenor) in Halliday's register theory is presented separately, they, in fact, mutually relate and depend on each other. The associated values of these paramete help us as translators or readers to determine the register and genre of the text. These parameters are not fixed in a text; they can be varied in a text and even in sentences. To understand the relationship between a text and register will help translators have reasonable deduction in discourse analysis process.

In Halliday's term, the relationship between metafunctions of language (ideational, textual and interpersonal) and the context variables (field, mode and tenor) is called realization, i.e. the way in which different types of fields, mode and tenor condition ideational, textual and interpersonal meaning [2]. In terms of semantics and pragmatics, field expresses interpersonal meaning, which is concerned with mapping the entity of the world realized through transitivity selection, patterns of lexical choices, collocations, use of onomatopoetic elements, etc. In the same way, mode expresses textual meaning through the channel (spoken/ written, etc.) and the degree of participation between writer and reader. Participation can be simple, i.e. a monologue with no addressee participation built into the text, or complex with various addressee-involving linguistic mechanisms characterizing the text. Textual means refer to textual cohesion, which is realized through a number of thematic structures, means of cohesion (additive, adversative, repetition, substitution, ellipsis, etc.). Finally, tenor expresses interpersonal meaning, which is realized through the nature of verb phrase, mood, tense, sentence structure, repetition, structure of noun phrase, etc. Thus, to achieve the equivalence in translation, texts (TT and ST) must be examined in the social contexts though the above three parameters. These parameters must be put into comparison between source and target contexts. As mentioned above, TQA is not easy at all for the assessors, however; to serve teaching and evaluating purposes, TQA criteria can be built for specific contexts. On the basis of the above arguments, it can be suggested to construct TQA criteria in translation teaching context, which can be generalized in a matrix below. The term "matrix" is proposed here because the assessors, researchers or teacher evaluators can also base on the contents in the matrix to develop other criteria in accordance with purposes of evaluation.

Table 1. TQA Criteria Matrix For Translation Teaching Context.

\begin{tabular}{|c|c|c|c|}
\hline Register & Field & Mode & Tenor \\
\hline Language & $\begin{array}{l}\text { Lexical choice } \\
\text { Lexical collocation } \\
\text { Transitivity }\end{array}$ & $\begin{array}{l}\text { Cohesionmodes } \\
\text { Information structure } \\
\text { Discourse style }\end{array}$ & $\begin{array}{l}\text { Modality } \\
\text { Speech acts } \\
\text { Connotative features } \\
\text { Grammar structures }\end{array}$ \\
\hline
\end{tabular}




\section{Research Methodology}

A survey on students' TQA activity will be conducted. The purposes of these surveys are to see how the students carry out peer assessment activity and to measure what extent TQA activity also affects students' translation competence. Thus, to achieve the survey results, the first experiment has been conducted with two groups of English- majored students at intermediate level of English, respectively named 55TA1, 55TA2 and each group consists of 40 students. The empirical participants will be totaled 80 third year students at Nha Trang University - Vietnam. To collect the data for the investigation, one group (55TA1) are instructed TQA criteria and practice assessment activity, while the other group (55TA2) are not introduced to the TQA criteria and also undertake the same assessment activity. The assessment activity is performed by the two selective groups with the same pieces of translated versions. Apart from assessment activity, a survey on students' translation ability is also implemented on the same piece of English source text. The outcomes of the surveys will be compared between the two selective groups.

\section{Findings and Data Analysis}

In regards to the assessment activity, the comparative results show that students in group 55TA1 employ the assessment activity faster and more actively in terms of time, procedure and attitude. Their evaluations are quite appropriate and founder as on able, which are proved by the given mark statistics. Out of a total of 40 students in group 55TA1, only $15 \%$ of them have different evaluation results, while students in the other group (55TA2)seem to be more passive and 77,5\% of students have assessed with high and low quality simultaneously (see table 2).

Table 2. A survey results about students'translation assessment activity.

\begin{tabular}{lll}
\hline \multicolumn{1}{c}{ Groups } & Group 55TA 1 & Group 55TA 2 \\
\cline { 1 - 1 } Outcomes & & \\
\hline Identical assessment outcome & $34(85 \%)$ & $9(22,5 \%)$ \\
Different assessment outcome & $6(15 \%)$ & $31(77,5 \%)$ \\
Total & 40 & 40 \\
\hline
\end{tabular}

With regards to translation activity, the result indicates that students in group 55TA1 perform their translation much better than that in group 55TA2. The statistics shows the percentage of students getting from 7 to 8 marks is $87,5 \%$ $(35 / 40)$ and the rest getting 6marks is $25 \%(5 / 40)$ (see table 3 ). Compared to the group 55TA2, the number of students getting 5 marks is the highest, while nobody gets 5 marks in group 55TA1. The percentage of students in group 55TA2 achieving 6 and 7 marks are 32,5\% and 12,5\% respectively, but only $0,2 \%$ of students get 8 marks (see table 3 below).

Based on the investigation into the two groups of students' translation competence, anyone equipped with knowledge of assessment criteria will definitely perform the translation activity better than the others who have no given-assessment criteria in advance.

In language teaching in general, thus, especially in teaching translation in particular, the TQA should be taken into account in the process of teaching and training.

Table 3. A survey results on students' translation ability.

\begin{tabular}{|c|c|c|c|c|}
\hline Group & 5 & 6 & 7 & 8 \\
\hline 55TA1 & $0(0 \%)$ & $5(12,5 \%)$ & $20(50 \%)$ & $15(37,5 \%)$ \\
\hline 55TA2 & $21(52,5 \%)$ & $13(32,5 \%)$ & $5(12,5 \%)$ & $1(0,2 \%)$ \\
\hline
\end{tabular}

\section{Conclusion}

The paper has discussed some problems related to TQA and provided theoretical ground for the application of Halliday's register model to construction of TQA criteria in translation teaching context. Translation is the matter of meaning and it is the matter of society, so the linguistic units make sense if only they are in a certain context of situation. In other words, meaning of text only happens in "context" rather than in vacuum. Based on the current translation training situation, levels of students and training purposes, the application of Halliday's register model in constructing TQA criteria has been suggested. These TQA criteria have been used in an empirical research for two selective group of language major students. It can be concluded that translation assessment activity will be vain if TQA criteria are not determined and given in advance. Besides, TQA activity itself with specifically gives criteria not only enforces students' discourse analysis skill, but also considerably improves students' autonomy and translation competence.

\section{References}

[1] Baker, M., \&Saldanha, G. (1998). Routledge encyclopedia of translation studies. New York: Routledge.

[2] Eggins, S. \& Martin, J. R. (1997). Genre and register of discourse. In T. van Dijk, (Ed), Discourse as structure and process (pp. 230). London: Sage.

[3] Halliday, M. A. K. (1964). The linguistics sciences and language teaching. London: Longman.

[4] Halliday, M. A. K. \&Hasan, R. (1989). Language, text and context: Aspects of language in Social-Semiotic Perspective. Victoria 3217: Deakin University.

[5] Hatim, B. \&Mason, I. (1990). Discourse and the translation. London/New York: Longman.

[6] Hatim, B. \& Mason, I. (1997). The translator as communicator. Routledge, London/ New York.

[7] Herman. (2016). The method of translation and practices. Germany: LAP LAMBERT Academic Publishing. ISBN: 9783-330-00145-9.

[8] Herman, Murni, S. M., Sibarani, B., Saragih, A. (2019), Structures of representational metafunctions of the "Cheng Beng" ceremony in Pematangsiantar: A multimodal analysis. International Journal of Innovation, Creativity and Change, 8 (4), 34-46. Available at: https://www.ijicc.net/images/vol8iss4/8403_Herman_2019_E _R.pdf. 
[9] House, J. (1981). A model for translation assessment. $2^{\text {nd }}$ edition. Tubingen: Gunter Narr.

[10] House, J. (1989). Reading in translation theory. Chesterman, A. (ed). Helsinki: Layman Kirjapaino.

[11] Melis, N. M \&Albir, A. H. (2001). Assessment in translation studies: Research needs. Meta: Translators' Journal, Vol: 46, No 2, 2001, P. 272-287.

[12] Newmark, P. (1988). A textbook of translation. Prentice Hall International.
[13] Nord, C. (1991). Text analysis in translation: Theory, methodology, and didactic application of a model for translation-oriented text analysis. Amsterdam-Atlanta: Rodopi.

[14] Van, H. V. (2003). Translation studies. Publishing House of Social Sciences.

[15] Williams, M. (2001). The application of argumentation theory to translation quality assessment. Translators' Journal. 46 (2). 326-344. 